\title{
Shifting towards a Mediterranean Diet in the US: How Far Do We Have to Go, What Are the Potential Health Benefits and Can We Get There?
}

\author{
Allison Cappelaere Righter ${ }^{1}$ and Arlin Wasserman ${ }^{2}$ \\ 1. Department of Culinary Science, The Culinary Institute of America, 1946 Campus Dr., \#246, Hyde Park, NY 12538, USA \\ 2. Menus of Change Sustainable Business Leadership Council, The Culinary Institute of America, 69 Church Street, Suite 4, Lenox, \\ MA 01240, USA
}

\begin{abstract}
In the public dialogue surrounding the development of the 2015 dietary guidelines for Americans, public health and environmental advocates converged around a simple theme of shifting towards a more plant-forward Mediterranean-style diet. A robust body of literature documenting the health benefits of this eating pattern provides compelling reasons to change our dietary habits in ways that also benefit our environment, but we also need to have the right foods available and affordable to support this modest shift. This commentary discusses the gaps in current US dietary intakes compared to recommendations for meat and protein versus plant-based foods and the potential health benefits of shifting towards a more plant-based diet, focusing on the complex role of Mediterranean crops, such as tree nuts and olive oils, needed to support this shift.
\end{abstract}

Key words: Nutrition, public health, sustainable, Mediterranean diet, environment, food systems, tree nuts, olive oil.

\section{Introduction}

Nationally, as the US government considered what its newest dietary guidelines should be, the sustainability has emerged as a major theme for shaping the country's official advice about what to eat. Environmental science has continued to document the high toll of food production, especially meat, while public health and nutrition science has continued to find new benefits of eating a diet that includes less meat and more plant-based foods than the typical American now consumes. In the public dialogue surrounding the development of the 2015 dietary guidelines for Americans, public health and environmental advocates converged around a simple theme of shifting towards a more plant-forward diet.

In the scientific report released in February 2015, the Dietary Guidelines Advisory Committee (DGAC) acknowledged that meeting current and future food

Corresponding author: Arlin Wasserman, M.Sc., research field: public health. and nutrition needs will depend on agricultural practices that conserve limited natural resources, and concluded that "a diet higher in plant-based foods... and lower in calories and animal-based foods is more health promoting and is associated with lesser environmental impact... than is the current average US diet" [1]. They noted that a wide variety of dietary patterns, including a Mediterranean-style and vegetarian diet, could meet our nutritional needs, while allowing for flexibility depending on personal preferences and cultural traditions.

While ultimately, the 2015 dietary guidelines will not include sustainability as a factor in its recommendations, the inclusion of this topic in the DGAC report sparked tremendous interest, with a record-breaking 29,000 public comments submitted by many prominent organizations and individuals supporting a more plant-forward diet [2, 3]. Plant-forward may be a new term, but it has grown out of more than a generation of scientific research into 
healthy diets, which has focused on the benefits of a Mediterranean-style diet.

The robust body of scientific evidence about the health benefits of the Mediterranean diet, along with more recent evidence about the health benefits of plant-forward diets provides compelling reasons to change our dietary habits in the US in ways that also benefit our environment. The change is relatively small (one or two servings or snacks a day), but it also needs to have the right foods available and affordable to support this modest shift at the population level. For example, research has indicated that eating more tree nuts and olive oil may play a substantial role in the health benefits achieved from a Mediterranean diet pattern [4].

California is one of the world's few agricultural regions that has a Mediterranean climate well-suited for growing tree nuts, i.e., almonds, pistachios and walnuts and olives, among other high value crops [5]. In fact, it is the largest producer of almonds, olives, fruits and vegetables in the US, in addition to the largest producer of tree nuts in the world [6]. But, the impact of drought and climate change on agricultural productivity in California and elsewhere is significant [7]. Some recommendations for how to address the resulting water scarcity also include reductions in water for agricultural production. With the drought and debate about water use pressuring California agriculture, we also wondered if change is coming too late, that is, will the US still be able to produce and eat a healthy plant-forward diet, like the Mediterranean diet? Or is severe drought in Mediterranean climates putting foods essential to the Mediterranean diet at risk? The analysis of the paper sought to explore and reconcile these conflicts and make the case that continuing to grow Mediterranean crops, like tree nuts and olive oil, in California is key to realizing the benefits of even a modest dietary shift in the US.

\section{Current US Eating Patterns Compared to Recommendations for Meat and Protein versus Plant-Based Foods}

By many widely accepted measures, the overall dietary quality of the average American has been persistently suboptimal, meaning that the nation overall has failed to meet both current guidelines as well as those newly proposed $[8,9]$. Compared to the healthy US-style food pattern at the 2,000 calorie level, as described in the latest DGAC report, Americans of ages two and older eat too much meat, refined grains, solid fats and sugars and too little fruits, vegetables, whole grains, dairy, beans and nuts (Fig. 1).

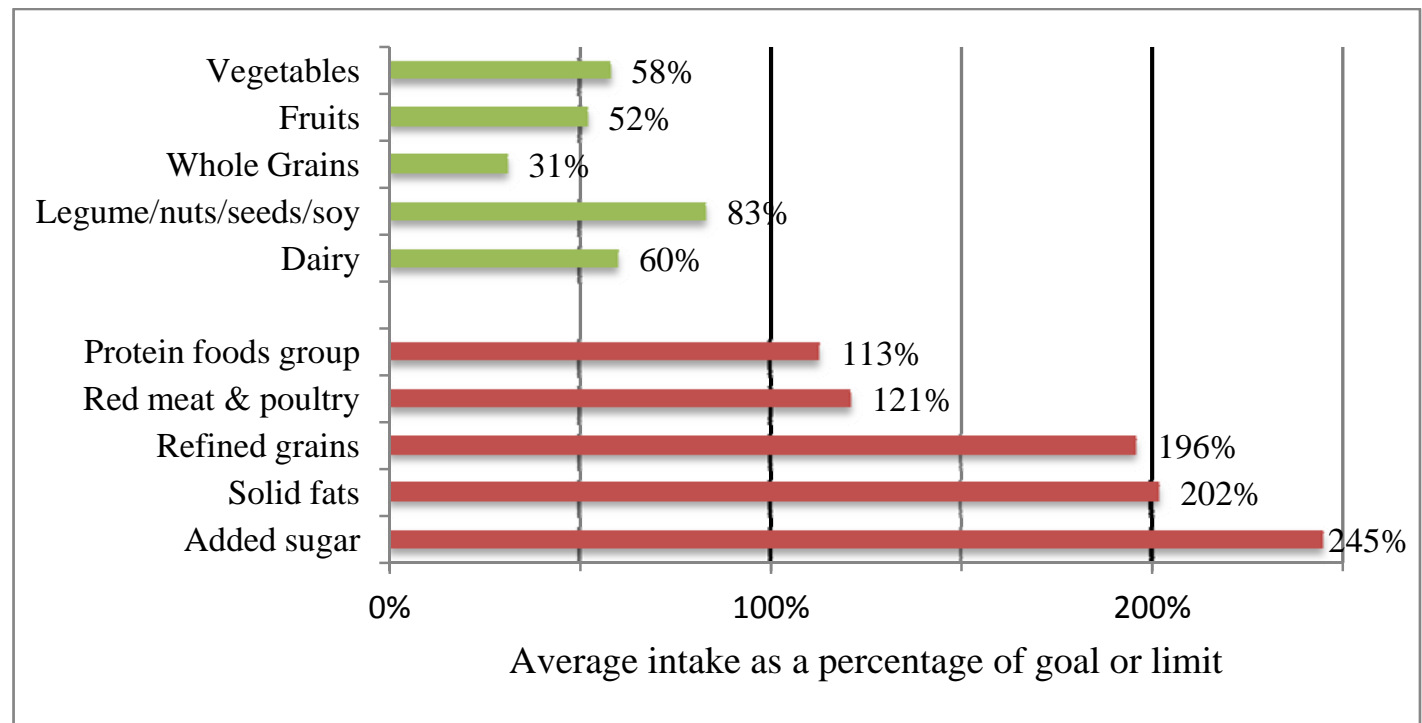

Fig. 1 Average US dietary intake ${ }^{1}$ compared to USDA healthy US-style of 2,000-calorie food pattern recommendation.

${ }^{1}$ Using NHANES, WWEIA 2011-2012 Food Patterns Equivalents Database (FPED) [10], compared to USDA Healthy US-Style Food Pattern for 2,000 calorie diet as described in Ref. [1]. 

What Are the Potential Health Benefits and Can We Get There?

Of particular concern is the low consumption of plant-based foods, such as vegetables, fruits, whole grains, legumes, nuts and seeds in relation to the high consumption of animal protein. According to national survey data released by the US Centers for Disease Control and Prevention, fewer than $20 \%$ of adults in the US are consuming the recommended daily servings for fruits and vegetables [11]. These results are consistent with an analysis by the American Health Association released in March 2015, which illustrated how Americans have consistently fallen significantly short by between 2 and 2.5 cups of the recommendations agreed upon by most health organizations to consume approximately 4.5 cups of fruits and vegetables a day [12]. Additionally, according to the DGAC scientific report, nearly everyone in the US fails to meet the goal for whole grain intake, despite slight increases over the last decade [1].

On the other hand, meat consumption in the US has nearly doubled over the last century [13, 14]. Americans are currently among the highest meat consumers in the world, eating nearly three times of the global average [15]. While beef consumption is beginning to decline in this country as poultry consumption increases, red meat-mostly beef and pork, still makes up the largest proportion of total meat consumed [14]. About a quarter of that is processed meat, such as bacon, cold cuts, sausages and meat snacks [13].

Recent estimates of average US meat and poultry intake per person range between 4.0 and 5.5 ounces per day, based on either dietary intake data or loss-adjusted agricultural supply data [16]. While there is generally a lack of specific federal dietary guidance on daily meat consumption, meat is categorized with other protein-rich foods in the "protein foods" group, which includes meat, seafood, eggs, soy-based products, legumes, nuts and seeds [17]. Estimated average US consumption of the protein foods group ranges between 6.2 and 7.4 “ounce equivalents” (oz-eq) ${ }^{1}$ per day [16], which is considerably higher by between $13 \%$ and $35 \%$ than the 5.5 oz-eq recommended in the healthy US-style food pattern recommendation for individuals consuming a 2,000 calorie diet (Fig. 2).

Notably, between two-thirds and three-quarters of estimated intake from the protein foods group currently comes from meat and poultry, of which more than half is red and/or processed meat [16]. For adults eating 2,000 calories per day, red meat and poultry intake should be 23 oz-eq per week, or approximately 3.3 oz-eq per day [1]. But, current intake estimates indicate that Americans are exceeding this recommendation by $0.7-2.2$ oz-eq per day, or by 21\%-66\%. Americans have ample room to shift eating habits towards more non-meat protein sources while still eating recommended levels of meat and poultry.

Analysis of intake and availability of protein, specifically as a nutrient, also reaches similar conclusions. Americans well-exceed official estimated average requirements and recommended daily allowances for protein, with requirements based on body weight [18]. The 2015 DGAC report confirmed that "intakes of protein (as $\mathrm{g} / \mathrm{d}$ ) are adequate across the population and protein is not a shortfall nutrient" [1]. While US consumers view protein as nearly synonymous with meat and animal products, approximately $35 \%$ of all protein available within the food supply also comes from grains and vegetables [16]. However, as with the protein foods group, the vast majority of our overall protein intake continues to come primarily from meat and animal sources [18] (Fig. 3).

Legumes, nuts, seeds and soy are important, nutrient-dense, plant-based protein foods that are less commonly consumed in the US. According to the DGAC report, the majority of the population does not

\footnotetext{
1 The use of "ounce-equivalents" (oz-eq) allows comparisons within food groups. In the MyPlate protein foods group, an ounce-equivalent is equal to one ounce of cooked lean meat (e.g., $1 / 4$ cup cooked beans, 1 tablespoon of peanut butter, or $1 / 2$ ounce of nuts/seeds).
} 


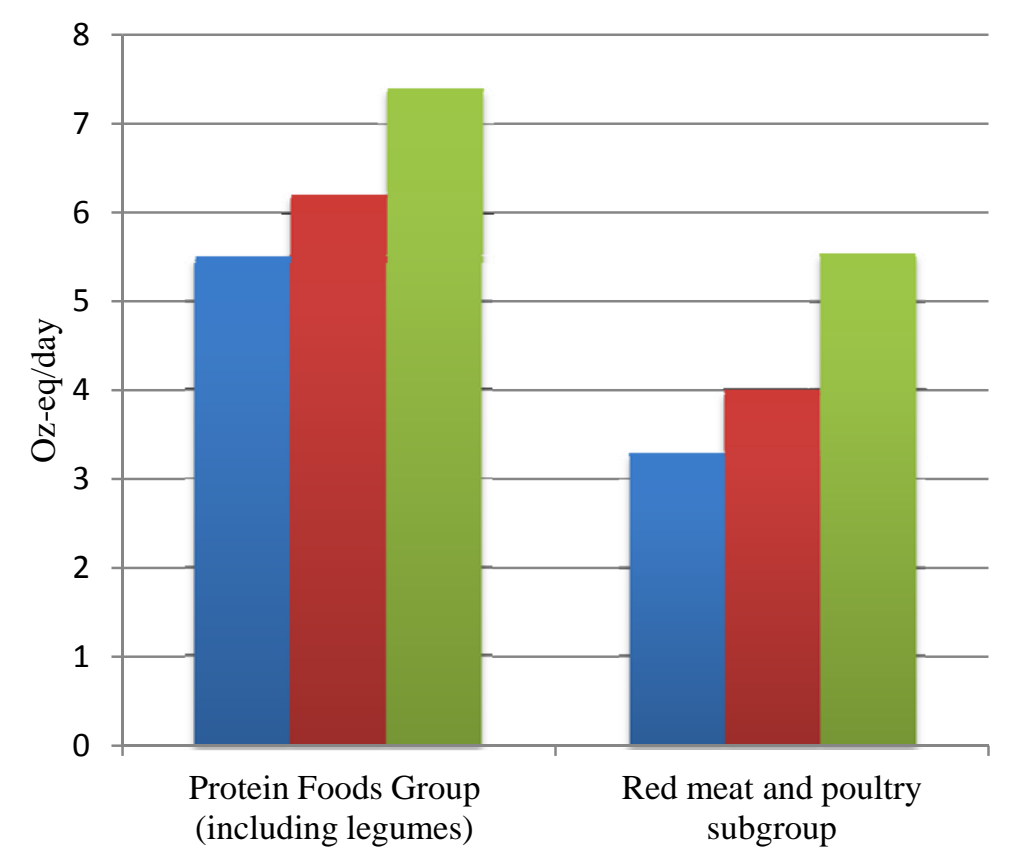

Recommended intake

n Current intake based on Dietary Intake Surveys

Current intake based on Per Capita Availability Data, adjusted for loss

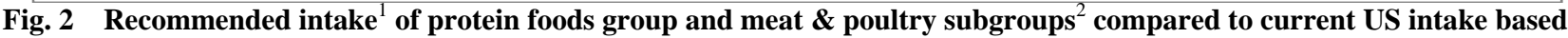
on dietary surveys ${ }^{3}$ and agricultural supply ${ }^{4}$ data.

${ }^{1}$ Recommended intakes based on USDA Healthy US-Style Food Pattern for 2,000 calorie diet, as described in Ref. [1]. The daily recommendation for protein foods is 5.5 oz-eq per day, while the meat and poultry subgroup recommendations are expressed as a weekly recommendation of 23 oz-eq per week, which it was calculated to be 3.3 oz-eq per day.

${ }^{2}$ The USDA protein foods group includes red meat, poultry, eggs, seafood, nuts/seeds, soy and legumes. One ounce equivalent is: 1 ounce lean meat, poultry, or seafood; 1 egg; $1 / 4$ cup cooked beans or tofu; 1 tbsp peanut butter; $1 / 2$ ounce nuts/seeds.

${ }^{3}$ Based on HANES 2011-2012 Food Patterns Equivalents Database (FPED) [10].

${ }^{4}$ Based on USDA Loss-Adjusted Food Availability Data, 2013, used in Ref. [16].

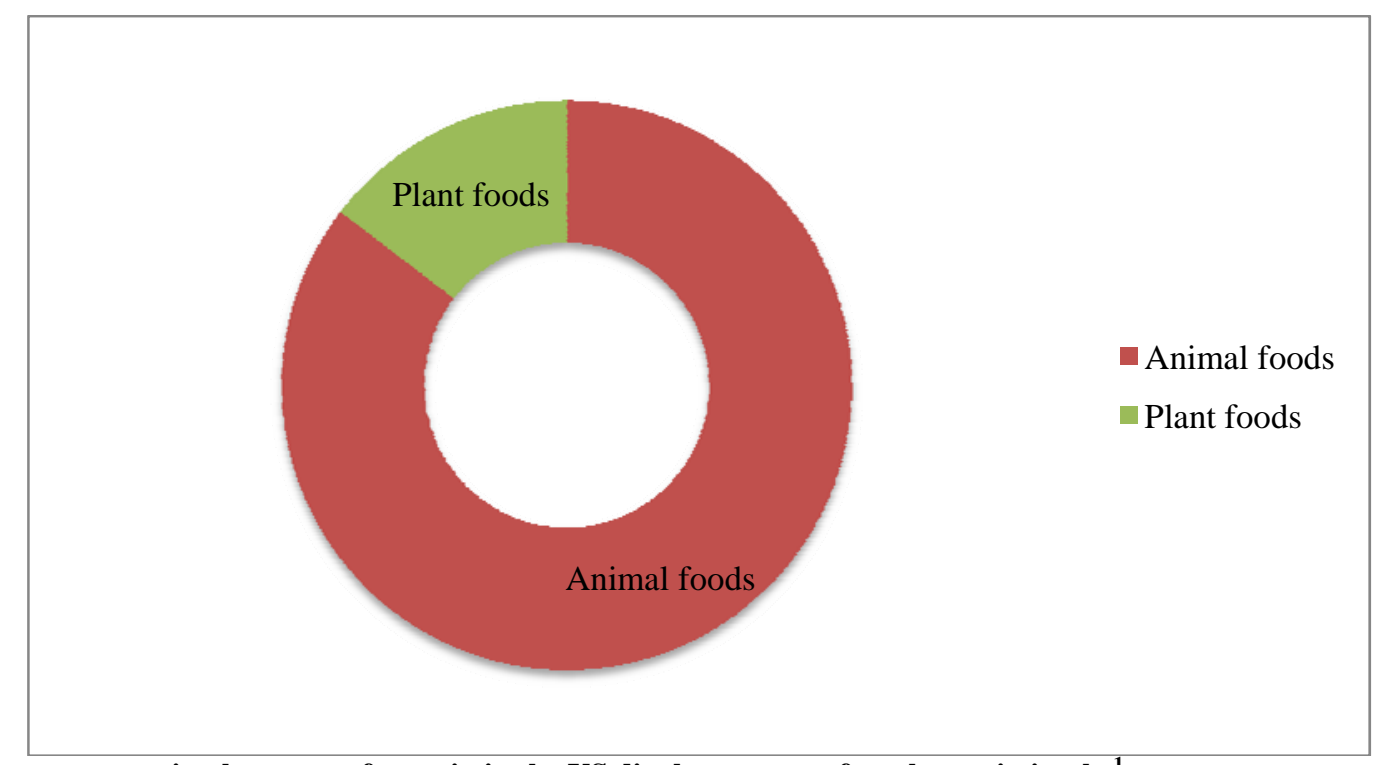

Fig. 3 Plant versus animal sources of protein in the US diet by percent of total protein intake ${ }^{\mathbf{1}}$.

${ }^{1}$ Animal foods include chicken, beef, pork, lamb, veal, turkey, milk, dairy, eggs, seafood and shellfish; plant foods include beans, legumes, peas, grains, peanuts and tree nuts, based on Ref. [18]. 


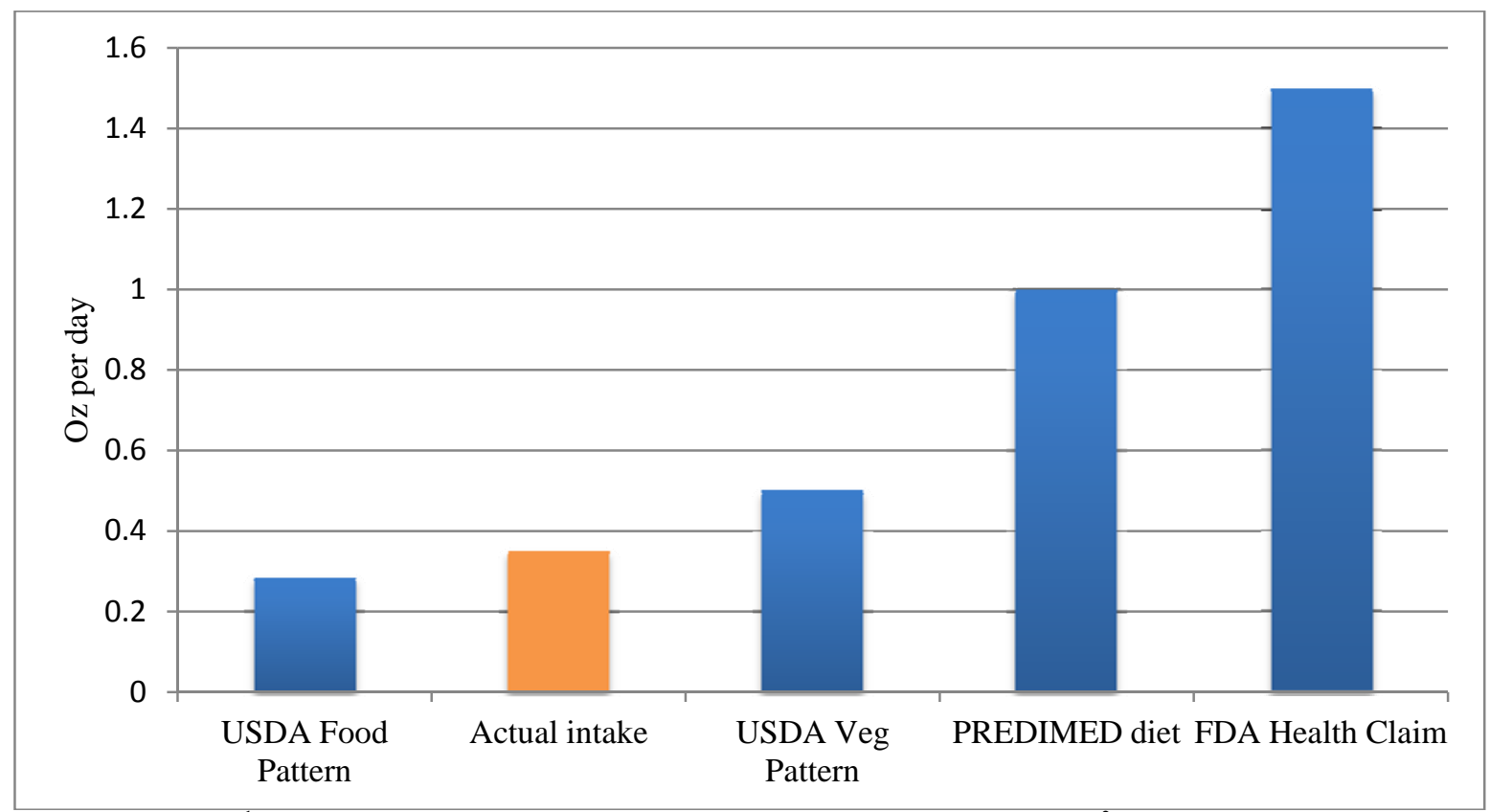

Fig. 4 Current intake ${ }^{1}$ compared to various recommended intake levels of nuts and seeds ${ }^{2}$.

${ }^{1}$ Actual intake based on NHANES 2011-2012, Food Pattern Equivalent Database [10].

${ }^{2}$ Recommended intake based on in the USDA Healthy US-Style Food Pattern and Vegetarian Dietary Pattern for 2,000 calorie diet, as described in Ref. [1], the amount supplemented in the PREDIMED clinical trials in Ref. [4] and FDA in Ref. [19].

meet the food pattern recommendations for these foods, which is a modest amount of 6 oz-eq per week (including 1.5 oz-eq/week of legumes, 4 oz-eq/week of nuts/seeds and 0.5 oz-eq/week of soy) [1]. For nuts and seeds, specifically, the food pattern recommendation of $4 \mathrm{oz}-\mathrm{eq}$ per week is comparable to only 2 oz per week, or a meager 0.29 oz per day ${ }^{2}$. While dietary intake data suggest that Americans currently on average slightly exceed this amount, most Americans do not. According to an analysis of NHANES data included in the DGAC report, overall approximately $60 \%$ of the population does not meet the food pattern recommendation for nuts, seeds and soy products [1].

The healthy vegetarian pattern described by the DGAC includes up to $0.5 \mathrm{oz}$ per day of nuts and seeds. There also are other dietary recommendations to eat nuts and seeds at higher levels to achieve health benefits (Fig. 4). This includes levels necessary for a qualified health claim approved by the US Food and Drug

\footnotetext{
${ }^{2}$ For nuts and seeds, one oz-eq is $1 / 2$ ounce. For ease of comparisons across sources, it will be converted to straight ounces.
}

Administration (1.5 oz/day) [19] and also the health benefits of eating a Mediterranean diet as found in the PREDIMED randomized trial in Spain (1 oz/day) [4].

Researchers have also begun to mine national dietary intake data even further to explore consumption trends for tree nuts, specifically, almonds. Based on an analysis of nut consumption among US adults using NHANES 2009-2010 data, almost $40 \%$ of adults consumed nuts (tree nuts, peanuts and seeds) on a given day, with $14.4 \%$ of men and $11.8 \%$ of women consuming more than 1.5 ounces [20]. This study also found that approximately $80 \%$ of nuts were consumed as single item foods or as nut butters. Additional analyses of recent NHANES data found much smaller segments of the population consumed tree nuts and almonds, 6.8\% [21] and 3.5\% [22], respectively.

While almonds and other nuts continue to be consumed primarily as a snack, sales for meat-based snacks, such as beef jerky and pork rinds, are increasing rapidly and growing 10 times faster than nuts, according to market research published in the 

What Are the Potential Health Benefits and Can We Get There?

May 2015 issue of the Snack Food Association's snack world publication [23]. With snacks now making up nearly half of all eating occasions in the US, as estimated by the Hartman Group, there is tremendous potential to close the dietary gap through a very modest shift in snacking choices back towards more nuts over meat-based options [24].

As examined in this section, the dietary quality of average US adults is consistently poor with too much meat and animal protein, and not enough plant-based foods, including fruits, vegetables, legumes, nuts and seeds. While there is still a long way to go towards meeting both current and newly recommended dietary guidelines, even very modest dietary shifts can help us begin to close this gap.

\section{Health Impacts and Benefits of Modest Dietary Changes}

According to the US Centers for Disease Control, chronic illness affects one of every two adults in the US [25] and accounts for more than three-quarters of total healthcare expenditures [26]. Dietary risks represent the leading causes of disease burden in the US and contribute to more than a quarter of all deaths per year, a total of more than 678,000 [27, 28].

A strong body of scientific evidence supports the basic assertion that a high meat diet increases risks of these diet-related diseases, while a diet rich in more plant-based foods decreases these same risks. Red meats and processed red meats, in particular, are consistently associated with higher risk of heart disease, stroke, type 2 diabetes, obesity, certain cancers and earlier death [29-35] (Fig. 5). The DGAC committee's examination of the relationship between foods consumption, dietary patterns and various health outcomes also concluded there is moderate to strong evidence that higher intake of red and processed meat is detrimental compared to lower intake [1].

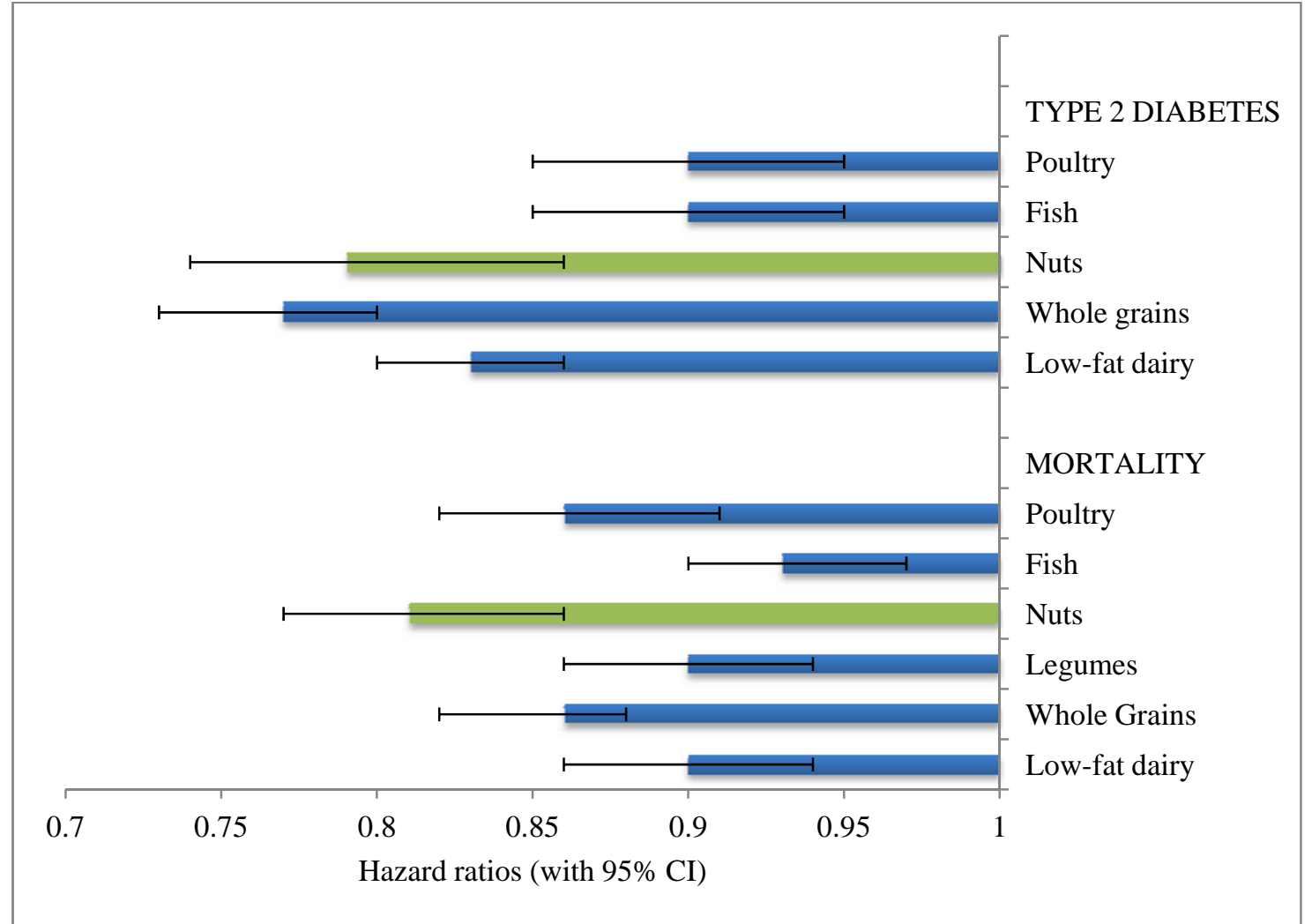

Fig. 5 Relative risk for type 2 diabetes $^{1}$ and all-cause mortality ${ }^{2}$ associated with substituting one serving of red meat per day.

${ }^{1}$ Data according to Ref. [32].

${ }^{2}$ Data according to Ref. [29]. 

What Are the Potential Health Benefits and Can We Get There?

In contrast, the inclusion of more fruits, vegetables, whole grains and other plant foods has been associated with many positive health outcomes. Vegetarian dietary patterns have been studied extensively and shown to contribute to decreased disease risks and to increased longevity [36-38]. However, a person does not need to become fully vegetarian to reap the benefits of including more plant foods in the diet. For example, increasing fruits and vegetables alone can reduce the risk of cardiovascular disease and stroke by 20\% [39]. A large long-term study from the Harvard School of Public Health has also shown that eating more whole grains (compared to little or no whole grains) may be associated with up to $15 \%$ lower mortality, particularly cardiovascular-related mortality [40].

Many studies have also shown positive health benefits from the regular and increased consumption of nuts (including all tree nuts, peanuts, and in some cases, soy) and seeds. Nuts and seeds are a valuable source of protein and also contain other important nutrients, such as mono and polyunsaturated fats, dietary fiber, vitamin E, magnesium, plant sterols and more [1]. Several of the largest cohort studies, primarily from the Harvard School of Public Health, have shown a consistent $30 \%$ to $50 \%$ lower risk of heart disease associated with eating nuts several times a week [41].

Regular nut consumption also is associated with lower risk of stroke and type 2 diabetes, with findings more inconsistent but generally related to a lesser degree [42-44]. Despite being calorie dense, regular nut consumption also is consistently found to be associated with better weight status [21]. Additionally, a recent Harvard analysis of nut consumption and mortality showed that individuals who eat nuts seven or more times per week had a $20 \%$ lower death rate from any cause compared with individuals who did not eat nuts [45]. Researchers from Vanderbilt recently confirmed these findings and observed similar reducing overall mortality and also death from cardiovascular disease across different ethnic groups and among individuals from lower socio-economic groups [46].

Tree nut consumption also has been shown to be associated with higher nutrient intakes and higher adherence to the dietary guidelines, suggesting that this food group can be a good marker of a healthy diet [47]. Further mining of the data for almond consumption, in particular, shows that almond eaters scored significantly higher in nutrient adequacy and dietary quality compared to non-almond eaters (and also by a large margin compared to those who eat a mix of tree nuts) [21]. A substantial body of nutrition research suggests that almonds, when eaten as part of a healthy diet, may have beneficial effects on heart health, body composition, diabetes and blood sugar control and weight maintenance, especially in overweight and obese adults [48].

Given the substantial body of scientific evidence that eating red meat increases health risks while eating nuts and other plant-based foods decreases these risks, researchers are beginning to quantify the specific population health benefits of substituting one serving of red meat in the diet for other sources of protein, like nuts. Two studies from the Harvard School of Public Health examined the reduction in relative risk for type 2 diabetes [32] and death from all-causes [29] from exchanging one serving per day of red meat for several other foods in very large populations.

These two studies find that eating one less serving of red meat per day and one more serving of nuts is associated with a 21\% lower risk of type 2 diabetes and a $19 \%$ lower risk of all-cause mortality. Notably, eating more nuts and less red meat offers some of the highest reductions in risk compared to eating more of other foods, and the reductions may also be higher for replacing processed red meat, like meat snacks with nuts. This provides convincing evidence of the significant health benefits that can come from even a very modest shift of replacing one serving of red meat for an equal serving of tree nuts, such as almonds, 

What Are the Potential Health Benefits and Can We Get There?

walnuts or pistachios.

The nutrition and public health community is also increasingly emphasizing the importance of promoting healthy dietary patterns rather than individual foods, with research rapidly evolving in this area. The Mediterranean diet has become one of the most popular and well-researched health-promoting eating patterns worldwide. Originally inspired by traditional dietary patterns of Greece, Southern Italy and Spain, it emphasizes an abundance of plant foods (including fruits and vegetables, whole grains, beans, nuts, and seeds), moderate amounts of seafood, poultry, olive oil, and wine and small amounts of dairy and red meat. The healthfulness of this dietary pattern has been corroborated by more than 50 years of epidemiological and clinical nutrition research documenting superior cardiovascular, cognitive, weight management and cancer outcomes [49]. Most of this evidence has come from simply observing health outcomes after the fact or experiments involving only small sample sizes.

However, a research group in Spain recently completed the largest randomized control trial to date of the Mediterranean diet used as primary prevention of cardiovascular disease [4]. Results show that the risk of cardiovascular diseases among this high risk population was reduced by $30 \%$ in both intervention groups eating a Mediterranean diet supplemented with either $30 \mathrm{~g}$ mixed nuts per day (15 g walnuts, $7.5 \mathrm{~g}$ almonds and $7.5 \mathrm{~g}$ hazelnuts) or extra virgin olive oil (50 mL per day), compared to the control group instructed to eat a low-fat diet. Interestingly, the interventions were intended to improve the overall dietary patterns, but the study found that the major differences in dietary intake at the end of the trial really only involved the supplemented nuts and olive oil. From this, the researchers conclude that "extra virgin olive oil and nuts were probably responsible for most of the observed benefits of the Mediterranean diets”, and that even greater benefits may be realized when compared with typical Western diets, as most of these study participants already eat diets that were similar to the Mediterranean diet [4].

A more recent subgroup analysis from these studies suggests that the Mediterranean diet may also reduce the onset of type 2 diabetes by about 30\% among adults with high cardiovascular risk and who do not have diabetes at the start of the study [50]. Additional analyses found that those who ate more than three servings of nuts per week had a 39\% reduced risk of early death as compared to those who did not eat nuts [51].

These impressive and robust scientific analyses demonstrate that nuts, olive oil and other plant-based foods play a critical role in health-promoting dietary patterns. While dietary patterns can be flexible to meet the needs and preferences of individuals, it is clear that shifting to a plant-forward diet can deliver significant health benefits. Based on the large prospective observational studies mentioned, people who consume nuts regularly may have a $30 \%$ or more reduced risk of heart disease, and perhaps to a lesser extent, stroke and type 2 diabetes. Associations with nut consumption and reduced overall mortality rates also seem to be consistently high and about 20\%, including the research on substituting nuts for red meat.

The results from the PREDIMED experimental trial [4] are particularly convincing, regarding the reduced risk of cardiovascular diseases and diabetes among individuals with a high risk of cardiovascular disease before starting on a Mediterranean diet that includes just over one ounce per day of nuts. If eating an ounce of nuts per day led to even conservative estimates in the reduction of risk and the instances of cardiovascular diseases, diabetes and stroke, this would represent significant public health benefits. Additional research is needed to better determine the extent of risk, but, for instance, a $20 \%$ reduction in the risk and rate of cardiovascular disease, below what most studies find, and a $10 \%$ reduction in the risk and rate of stroke and type 2 diabetes where less research 
Table 1 Potential death avoidance from exchanging one serving of red meat for one serving of nuts per day.

\begin{tabular}{llll}
\hline Disease & Deaths/year ${ }^{1}$ & Reduction & Reduction in mortality \\
\hline Cardiovascular diseases & 611,105 & $20 \%$ & 122,221 \\
Stroke & 128,978 & $10 \%$ & 12,898 \\
Diabetes & 75,578 & $10 \%$ & 7,558 \\
\hline Total avoided deaths & & 142,677 \\
\hline${ }^{1}$ Data according to Ref. [26]. & &
\end{tabular}

Table 2 Potential disease avoidance from exchanging one serving of red meat for one serving of nuts per day.

\begin{tabular}{llll}
\hline Disease & Cases/year $^{1}$ & Reduction & Reduction in cases \\
\hline Cardiovascular diseases & 19.4 million & $20 \%$ & $3,880,000$ \\
Stroke & 3.7 million & $10 \%$ & 370,000 \\
Diabetes & 21.2 million & $10 \%$ & $2,120,000$ \\
\hline Total avoided cases of disease & & & $6,370,000$ \\
\hline
\end{tabular}

${ }^{1}$ Data according to Ref. [27].

has been conducted and much below what most studies find, would result in approximately 140,000 fewer deaths (Table 1) and 6.3 million fewer people suffering from these diseases (Table 2).

\section{Is the Mediterranean Diet at Risk?}

The health benefits of making a modest dietary shift towards a more plant-forward Mediterranean-style diet, perhaps done at snack time for many, are compelling. One can also make an equally strong case for this dietary shift based on the potential environmental benefits, in terms of reduced greenhouse gas emissions and land and water usage. Collectively, these arguments raise the perceived value of producing foods that are essential to realize the health and environmental benefits of a plant-forward diet in the US and around the world. But we are also not certain to get there.

The future of the Mediterranean diet is connected to the decisions made about how to prioritize water use during droughts and the success or failure of agricultural crops grown in Mediterranean regions. The areas surrounding the Mediterranean Sea comprise the largest region in the world with the specific type of climate needed to produce olives, tree nuts and a handful of other crops that feed the world's demand for a Mediterranean-style eating pattern. There are only four other regions in the world that support this type of agriculture, including coastal California, Central Chile, the Western Cape of South Africa, and Western and Southern Australia [52].

California's Central Valley has emerged as the most productive almond region in the world with rapid expansion of almond acreage beginning in the 1960s [53]. Because of its ideal growing conditions, water infrastructure, and innovative technology and research, California now produces more than $80 \%$ of the world's almonds and almost all of the almonds eaten in the US [54]. With US consumption exceeding 642 million pounds in 2013-2014, the rest of the world is already unable to produce enough almonds to meet our current dietary demands (455 million pounds of non-US production) [54].

Similarly, Spain is the world's largest producer of olives and olive oil, accounting for 50\% of total global supply, followed by Italy, Greece and Turkey [55]. Olive oil is also produced domestically, with approximated 30,000 acres of olives planted across California and a few other states [56]. While Spain and Italy both produce and consume more olive oil per capita than in the US, consumption in the US has increased. According to the American Olive Oil Producers Association, US consumers use 80 million gallons of olive oil annually, making it the largest market outside of Europe [56].

As we begin to shift diets in this direction, the 
ability to grow the foods central to this diet is at risk from climate change, drought and challenging growing conditions in every Mediterranean growing region around the world. And the ability to provide more people with a Mediterranean diet relies on finding ways to maintain production in these regions and to overcome significant environmental challenges. For example, drought conditions in California in recent years have already begun to affect both almond and olive oil production, leading to modest declines in yields [57, 58]. Similarly, more frequent droughts in Spain and pestilence in Italy have also prompted fears of diminished olive oil production and increasing prices [59].

Health and environmental interests groups already are working to address the global challenge of climate change and drought by continuing to advocate for dietary shifts towards a plant-forward Mediterranean dietary pattern in the US and around the world. That is to say, we can eat our way out of the problem, at least in part, by shifting towards a plant-forward Mediterranean diet. For example, as we reduce consumption of red meat, we can cut back the amount of water used for livestock production including growing alfalfa and other animal feed crops in California [60].

But we must also prioritize the continued production of crops that support this shift. Any decisions about prioritization of water usage for during droughts in California and in those few other countries with Mediterranean growing conditions need to take into consideration long term effects on production. At least for almonds, research has shown that decision to cut back on irrigation water for a single season will reduce production for at least several more years [57].

If state, local and national priorities align for both what we should eat and what we should grow, as water becomes more scare, those problems can be solved. Public health and environmental scientists, interest groups and policy makers should continue promoting achievable, modest dietary shifts as one of the best ways to improve both our health and our environment. Based on the analysis, they should also be supporting the continued production of crops that are central to realize the health benefits of a plant-forward diet and that can only be grown in California and other Mediterranean climates.

\section{Conclusions}

This analysis addressed the potential health benefits of shifting towards a plant-based Mediterranean diet in the US and discussed opportunities for closing the gap compared to current dietary intakes. Taking into consideration the complex role of Mediterranean crops, such as tree nuts and olive oil, needed to support this shift, it was recommended that public health and environmental scientists work with policy makers to prioritize the continued production of these crops, while working to overcome significant environmental challenges. The future of the Mediterranean diet will depend on it.

\section{References}

[1] US Department of Agriculture and Health and Human Services. 2015. "Scientific Report of the 2015 Dietary Guidelines Advisory Committee.” Accessed July 9, 2015. http://health.gov/dietaryguidelines/2015-scientific-report/ PDFs/Scientific-Report-of-the-2015-Dietary-GuidelinesAdvisory-Committee.pdf.

[2] My Plate, My Planet: Food for a Sustainable World. 2015. "The Dietary Guidelines Advisory Committee Report: Support for Sustainability in the Public Comments." Accessed December 22, 2015. http://www.myplatemyplanet.org/downloads/2_Comment s Analysis_Final.pdf.

[3] American College of Lifestyle Medicine. 2015. "700 Doctors, Health Professionals, Include the American College of Lifestyle Medicine Support Dietary Guidelines to Eat Less Meat, More Plants.” Accessed July 9, 2015. http://www.prweb.com/releases/2015/05/ prweb12746348.htm.

[4] Estruch, R., Ros, E., Salas-Salvadó, J., Covas, M. I., Corella, D., Arós, F., Gómez-Gracia, E., Ruiz-Gutiérrez, V., Fiol, M., Lapetra, J., Lamuela-Raventos, R. M., Serra-Majem, L., Pintó, X., Basora, J., Muñoz, M. A., Sorlí, J. V., Martínez, J. A., and Martínez-González, M. 

What Are the Potential Health Benefits and Can We Get There?

A. 2013. "Primary Prevention of Cardiovascular Disease with a Mediterranean Diet.” N. Engl. J. Med. 368 (14): 1279-90.

[5] USDA-National Agricultural Statistics Service. 2015. "California Agricultural Statistics, 2013 Crop Year." Accessed April 2015. http://www.nass.usda.gov/Statistics_by_State/California/ Publications/California_Ag_Statistics/2013cas-all.pdf.

[6] California Department of Food and Agriculture. "Fruit and Nut Crops.” California Agricultural Statistics Review 2013-2014. Accessed January 10, 2016. https://www.cdfa.ca.gov/statistics/pdfs/2013/FruitandNut. pdf.

[7] USDA Economic Research Service. 2016. "California Drought: Farm and Food Impacts.” Accessed January 4, 2016. http://www.ers.usda.gov/topics/in-the-news/ california-drought-farm-and-food-impacts.aspx.

[8] Wang, D. D., Leung, C. W., Li, Y. P., Ding, E. L., Chiuve, S. E., Hu, F. B., and Willett, W. C. 2014. "Trends in Dietary Quality among Adults in the United States, 1999 through 2010.” JAMA Intern. Med. 174 (10): 1587-95.

[9] Krebs-Smith, S. M., Guenther, P. M., Subar, A. F., Kirkpatrick, S. I., and Dodd, K. W. 2010. "Americans Do Not Meet Federal Dietary Recommendations.” J. Nutr. 140 (10): 1832-8.

[10] US Department of Agriculture, Agricultural Research Service. 2014. "What We Eat in America (WWEIA), NHANES 2011-2012, Food Patterns Equivalents Data Tables.” Accessed July 2015. http://www.ars.usda.gov/ Services/docs.htm?docid $=23868$.

[11] Moore, L. V., and Thompson, F. E. 2013. "Adults Meeting Fruit and Vegetable Intake Recommendations, United States, 2013.” Weekly 64 (26): 709-13.

[12] The American Heart Association. 2015. "Helping Americans Eat More of the Good Stuff.” Accessed March 2015. http://www.heart.org/idc/groups/heart-public/@ private/@wcm/@fc/documents/downloadable/ucm_4737 60.pdf.

[13] Daniel, C. R., Cross, A. J., Koebnick, C., and Sinha, R. 2011. "Trends in Meat Consumption in the USA.” Public Health Nutr. 14 (4): 575-83.

[14] Larsen, J. 2012. "Peak Meat: US Meat Consumption Falling.” Earth Policy Institute. Accessed March 7, 2012. http://www.earth-policy.org/data_highlights/2012/highlig hts25.

[15] Food and Agriculture Organization of the United Nations. 2009. "The State of Food and Agriculture: Livestock in the Balance." Accessed July 10, 2015. http://www.fao.org/docrep/012/i0680e/i0680e.pdf.

[16] Fehrenbach, K. S., Righter, A. C., and Santo, R. E. 2016. "A Critical Examination of the Available Data Sources for Estimating Meat and Protein Consumption in the USA.” Public Health Nutr. 19 (8): 1358-67.

[17] US Department of Agriculture. 2015. "MyPlate Food Groups.” Accessed July 10, 2015. http://myplate.gov/food-groups/.

[18] Gardner, C., Hartle, J., Offringa, L., Garrett, R., and Wasserman, A. 2016. "Amount and Type of Protein Produced and Consumed in America: Maximizing the Intersection of Human Health and the Health of the Environment.” Nutrition Reviews (under Review).

[19] US Food and Drug Administration. 2003. "Qualified Health Claims about Cardiovascular Disease Risk: Nuts \& Heart Disease.” Accessed July 14, 2015. http://www.fda.gov/Food/IngredientsPackagingLabeling/ LabelingNutrition/ucm073992.htm\#cardio.

[20] Nielsen, S. J., Kit, B. K., and Ogden, C. L. 2014. "Nut Consumption among US Adults, 2009-2010.” NCHS Data Brief No. 176. Accessed December 2014. http://www.cdc.gov/nchs/products/databriefs/db176.htm.

[21] O’Neil, C. E., Fulgoni, V. L., and Nicklas, T. A. 2015. "Tree Nut Consumption Is Associated with Better Adiposity Measures and Cardiovascular and Metabolic Syndrome Health Risk Factors in US Adults: NHANES 2005-2010.” Nutr. J. 14: 64.

[22] O’Neil, C. E., Nicklas, T. A., and Fulgoni, V. L. 2016. "Almond Consumption Is Associated with Better Nutrient Intake, Nutrient Adequacy and Diet Quality in Adults: National Health and Nutrition Examination Survey 2001-2010." Food and Nutrition Sciences 7: 504-15.

[23] Watson, E. 2015. "New Data Reveals Winners in the US Snacks Aisle: RTE Popcorn, Bean Chips \& Dried Meat Snacks.” Accessed May 26, 2015. http://www.foodnavigator-usa.com/Markets/Winners-inUS-snacks-aisle-SkinnyPop-Beanitos-Way-Better-Snacks.

[24] The Hartman Group, Inc.. 2015. "Modern Eating: Cultural Roots, Daily Behaviors.” Accessed July 10, 2015. http://store.hartman-group.com/modern-eating-cultural-ro ots-daily-behaviors/.

[25] Centers for Disease Control and Prevention. "Chronic Disease Overview.” Accessed August 11, 2015. http://www.cdc.gov/chronicdisease/overview/.

[26] Murray, C. J. L., Abraham, J., Ali, M. K., et al. 2013. "The State of US Health, 1990-2010: Burden of Diseases, Injuries and Risk Factors.” JAMA 310 (6): 591-608.

[27] Centers for Disease Control and Prevention. 2013. "FastStats—Deaths and Mortality." Accessed August 11, 2015. http://www.cdc.gov/nchs/fastats/deaths.htm.

[28] Chatterjee, A., Kubendran, S., King, J., and DeVol, R. 2014. "Checkup Time: Chronic Disease and Wellness in America.” Milken Institute. Accessed January 29, 2014. http://www.milkeninstitute.org/publications/view/618. 

What Are the Potential Health Benefits and Can We Get There?

[29] Micha, R., Wallace, S. K., and Mozaffarian, D. 2010. "Red and Processed Meat Consumption and Risk of Incident Coronary Heart Disease, Stroke and Diabetes Mellitus: A Systematic Review and Meta-Analysis.” Circulation. 121 (21): 2271-83.

[30] Pan, A., Sun, Q., Bernstein, A. M., Schulze, M. B., Manson, J. E., Stampfer, M. J., Willett, W. C., and Hu, F. B. 2012. "Red Meat Consumption and Mortality: Results from Two Prospective Cohort Studies.” Arch. Intern. Med. 172 (7): 555-63.

[31] Sinha, R., Cross, A. J., Graubard, B. I., Leitzmann, M. F., and Schatzkin, A. 2009. "Meat Intake and Mortality: A Prospective Study of over Half a Million People.” Arch. Intern. Med. 169 (6): 562-71.

[32] Kaluza, J., Wolk, A., and Larsson, S. C. 2012. "Red Meat Consumption and Risk of Stroke: A Meta-Analysis of Prospective Studies.” Stroke. 43 (10): 2556-60.

[33] Pan, A., Sun, Q., Bernstein, A. M., Schulze, M. B., Manson, J. E., Willett, W. C., and Hu, F. B. 2011. "Red Meat Consumption and Risk of Type 2 Diabetes: 3 Cohorts of US Adults and an Updated Meta-Analysis.” Am. J. Clin. Nutr. 94 (4): 1088-96.

[34] Wang, Y., and Beydoun, M. A. 2009. "Meat Consumption Is Associated with Obesity and Central Obesity among US Adults.” Int. J. Obes. (London) 33 (6): 621-8.

[35] World Cancer Research Fund/American Institute for Cancer Research. 2007. "Food, Nutrition, Physical Activity and the Prevention of Cancer: A Global Perspective.” AICR, Washington, DC. Accessed August 11, 2015. http://www.aicr.org/assets/docs/pdf/reports/ Second_Expert_Report.pdf.

[36] Craig, W. J., and Mangels, A. R. 2009. "Position of the American Dietetic Association: Vegetarian Diets.” J. Am. Diet Assoc. 109 (7): 1266-82.

[37] Orlich, M. J., Singh, P. N., Sabaté, J., Jaceldo-Siegl, K., Fan, J., Knutsen, S., Beeson, W. L., and Fraser, G. E. 2013. "Vegetarian Dietary Patterns and Mortality in Adventist Health Study 2.” JAMA Intern. Med. 173 (13): 1230-8.

[38] Crowe, F. L., Appleby, P. N., Travis, R. C., and Key, T. J. 2013. "Risk of Hospitalization or Death from Ischemic Heart Disease among British Vegetarians and Nonvegetarians: Results from the EPIC-Oxford Cohort Study.” Am. J. Clin. Nutr. 97 (3): 597-603.

[39] He, F. J., Nowson, C. A., Lucas, M., and MacGregor, G. A. 2007. "Increased Consumption of Fruit and Vegetables Is Related to a Reduced Risk of Coronary Heart Disease: Meta-Analysis of Cohort Studies.” J. Hum. Hypertens. 21 (9): 717-28.

[40] Wu, H. Y., Flint, A. J., Qi, Q. B., Van Dam, R. M., Sampson, L. A., Rimm, E. B., Holmes, M. D., Willett, W. C., Hu, F. B., and Sun, Q. 2015. “Association between
Dietary Whole Grain Intake and Risk of Mortality: Two Large Prospective Studies in US Men and Women.” JAMA Intern. Med. 175 (3): 373-84.

[41] Harvard T.H. Chan: School of Public Health. 2015. "Nuts for the Heart.” Accessed August 11, 2015. http://www.hsph.harvard.edu/nutritionsource/nuts-for-the -heart/.

[42] Zhang, Z., Xu, G., Wei, Y., Zhu, W., and Liu, X. 2015. "Nut Consumption and Risk of Stroke." Eur. J. Epidemiol. 30 (3): 189-96.

[43] Shi, Z. Q., Tang, J. J., Wu, H., Xie, C. Y., and He, Z. Z. 2014. "Consumption of Nuts and Legumes and Risk of Stroke: A Meta-Analysis of Prospective Cohort Studies.” Nutr. Metab. Cardiovasc. Dis. 24 (12): 1262-71.

[44] Luo, C., Zhang, Y., Ding, Y., Shan, Z., Chen, S., Yu, M., Hu, F. B., and Liu, L. 2014. "Nut Consumption and Risk of Type 2 Diabetes, Cardiovascular Disease, and All-Cause Mortality: A Systematic Review and Meta-Analysis.” Am. J. Clin. Nutr. 100 (1): 256-69.

[45] Bao, Y., Han, J. L., Hu, F. B., Giovannucci, E. L., Stampfer, M. J., Willett, W. C., and Fuchs, C. S. 2013. "Association of Nut Consumption with Total and Cause-Specific Mortality.” N. Engl. J. Med. 369 (21): 2001-11.

[46] Luu, H. N., Blot, W. J., Xiang, Y. B., Cai, H., Hargreaves, M. K., Li, H. L., Yang, G., Signorello, L., Gao, Y. T., Zheng, W., and Shu, X. O. 2015. "Prospective Evaluation of the Association of Nut/Peanut Consumption with Total and Cause-Specific Mortality.” JAMA Intern. Med. 175 (5): 755-66.

[47] O’Neil, C. E., Nicklas, T. A., and Fulgoni, V. L. 2015. "Tree Nut Consumption Is Associated with Better Nutrient Adequacy and Diet Quality in Adults: National Health and Nutrition Examination Survey 2005-2010.” Nutrients 7 (1): 595-607.

[48] Almond Board of California. 2015. "Nutrition Research Reference List.” Accessed September 9, 2015. http://www.almonds.com/sites/default/files/misc/HP/Doc uments/almonds_nutrition_and_scientific_research_updat ed_august_2015.pdf.

[49] Oldways. 2015. “Med Diet \& Health.” Accessed July 13, 2015. http://oldwayspt.org/resources/heritage-pyramids/ mediterranean-diet-pyramid/med-diet-health.

[50] Salas-Salvadó, J., Bulló, M., Estruch, R., Ros, E., Covas, M. I., Ibarrola-Jurado, N., Corella, C., Arós, F., Gómez-Gracia, E., Ruiz-Gutiérrez, V., Romaguera, D., Lapetra, J., Lamuela-Raventós, R. M., Serra-Majem, L., Pintó, X., Basora, J., Muñoz, M. A., Sorlí, J. V., and Martínez-González, M. A. 2014. "Prevention of Diabetes with Mediterranean Diets: A Subgroup Analysis of a Randomized Trial.” Ann. Intern. Med. 160 (1): $1-10$. 

What Are the Potential Health Benefits and Can We Get There?

[51] Guasch-Ferré, M., Bulló, M., Martínez-González, M. A., Ros, E., Corella, D., Estruch, R., Fitó, M., Arós, F., Wärnberg, J., Fiol, M., Lapetra, J., Vinyoles, E., Lamuela-Raventós, R. M., Serra-Majem, L., Pintó, X., Ruiz-Gutiérrez, V., Basora, J., and Salas-Salvadó, J. 2013. "Frequency of Nut Consumption and Mortality Risk in the PREDIMED Nutrition Intervention Trial.” BMC Med. 11: 164.

[52] Chand, S. 2015. "Mediterranean Agriculture: Location and Characteristics (with Diagrams).” Accessed August 11, 2015. http://www.yourarticlelibrary.com/agriculture/ mediterranean-agriculture-location-and-characteristics-wi th-diagrams/25443/.

[53] Mura, J. R., Carmon, H., and Alston, J. 1993. "With Fewer Acres, More Mechanization: California Leads Spain in Almond Production, Exports to the World.” California Agriculture 47 (6): 11-4.

[54] The Almond Board of California. 2013. "Almond Almanac 2013.” Accessed August 11, 2015. http://www.almonds.com/sites/default/files/content/attach ments/2013_almanac.pdf.

[55] International Olive Council. 2015. "World Table Olive
Figures.” Accessed August 11, 2015. http://www.internationaloliveoil.org/estaticos/view/132world-table-olive-figures.

[56] American Olive Oil Producer's Association. 2015. “The American Olive Oil Industry Facts.” Accessed August 11, $2015 . \quad$ http://www.aoopa.org/ USOliveOilProductionFacts-i-17-2.html.

[57] University of California Agriculture and Natural Resources. 2015. "Drought Management for California Almonds: Impacts of Stress on Almond Growth and Yield.” ANR Publication 8515. Accessed February 2015. http://anrcatalog.ucanr.edu.

[58] Rodriguez, R. 2014. "Weather Woes Cost California Olive Growers Nearly Half the Crop.” The Fresno Bee. Accessed August 12, 2015. http://www.fresnobee.com/ news/business/agriculture/article19523235.html.

[59] Philips, A. 2014. "A Mega Drought Is Threatening to Drive up Olive Oil Prices.” Climate Progress. Accessed August 16, 2015. http://thinkprogress.org/climate/2014/ 08/16/3472137/spain-drought-olive-oil-california/.

[60] California Department of Water Resources (DWR). 2014. Statewide Water Balances, 1998-2010. 